\title{
A arte de contar histórias como dispositivo em acompanhamento terapêutico
}

Wiliam Siqueira Peres

Professor do Departamento

de Psicologia Clínica.

Faculdade de Psicologia.

Universidade Estadual Paulista

"Júlio de Mesquita Filho".

Mariana Pereira de Vasconcelos

Participante da prática de Psicologia

de acompanhamento terapêutico.

Faculdade de Psicologia.

Universidade Estadual Paulista

"Júlio de Mesquita Filho".
Universidad y salud /

Intervenciones

\section{Resumo}

Construímos a partir do acompanhamento terapêutico em saúde mental pública possibilidades de atenções psicossociais voltadas para ressocialização e inclusão em redes sociais emancipatórias de pessoas atravessadas pela exclusão, e, colocadas como frágeis. Ao criticar as referências que associam pessoas cegas como dependentes, privilegiamos a emergência das estilísticas da existência, ou seja, estilos de viver referimo-nos a um cuidado de si orientado por uma ética. Pretendemos colocar novas questões quanto à prática da Psicologia em seus atendimentos, reabilitação e possibilidades de transformação no modo de suas vivências, bem como elevar sua auto-estima pela potencialidade para desejar outros possíveis a fim de proporcionar independência e autonomia.

\author{
Palavras-chave \\ - saúde mental \\ - cuidado de si \\ - acompanhamento terapêutico \\ - deficiência visual \\ - contar histórias
}

\section{Introdução}

Pretendemos neste trabalho abordar como a metodologia de contações de histórias, em interfaces com o acompanhamento terapêutico (AT), pode ser um dispositivo no acompanhamento psicossocial de pessoas comprometidas pela cegueira. A ideia de dispositivo aqui surge como ferramenta teórica conceitual de auxilio nas problematizações das demandas trazidas pelo paciente, sendo o mesmo definido por Gilles Deleuze como:

"um emaranhado, um conjunto multilinear. Ele é composto de linhas de natureza diferente. E estas linhas do dispositivo não cercam ou não delimitam sistemas homogêneos, o objeto, o sujeito, a língua, etc., mas seguem direções, traçam processos sempre em desequilíbrio, às vezes se aproximam às vezes se afastam umas das outras. Cada linha é quebrada, submetida a variações de direção, bifurcante e engalhada, submetida a derivações" (Deleuze, 1988:1).

Esses lineamentos nos remetem a pensar sobre a produção dos sujeitos, os quais as linhas se processam como modos de subjetivação, como efeitos dos entrelaçamentos que podem configurar tanto um sujeito normatizado, como em vias de singularização.

Nesta perspectiva nos distanciamos de uma psicologia do indivíduo para privilegiar uma psicologia política e emancipatória, nas quais o contexto social, político e coletivo é tomado como pano de fundo dos acontecimentos e experiências vividas por esses sujeitos. A realização do trabalho em questão nos insere, primeiramente, na proposta de estágio curricular e orienta-nos por propostas críticas de atenção à saúde psicossocial de promoção e respeito aos direitos humanos. O núcleo de estágio é vinculado ao Departamento de Psicologia Clínica, da UNESP e faz parte do curriculum obrigatório do curso de Psicologia. Há oito anos, o estágio desenvolve o trabalho junto a uma unidade de Estratégia Saúde da Família (ESF), situada numa vila periférica da cidade de Assis, São Paulo. Observamos um bairro com poucos recursos sociais, comprometido com o tráfico de drogas, no qual os habitantes possuem baixa- renda e são excluídos de políticas públicas inclusivas.

O estágio atende as demandas do bairro por meio de atendimentos individuais e em grupos, em que são atendidos: usuários de drogas, mulheres que sofrem violências, pessoas com depressão, esquizofrenias e deficientes físicos e sensoriais.

O pedido do atendimento aqui focado aconteceu há quatro anos, com a família de um paciente que havia perdido a visão, atendido nos anos anteriores por outras estagiárias, caracterizado por sua revolta e não aceitação da situação adquirida, sob nossa responsabilidade nos últimos dois anos. Trata-se de uma família pobre, branca e religiosa, composta por cinco pessoas: o paciente, a esposa, dois filhos e uma filha, habitando uma moradia de fundos cedida por outros familiares. A renda familiar oriunda do trabalho doméstico realizado pela esposa e do benefício por invalidez do paciente.

Nosso atendimento com esse paciente não se orienta por uma visão individualista, pois partimos do pressuposto de um sujeito coletivo, sendo assim, todas as demandas e manifestações apresentadas são problematizadas como expressão de um coletivo, tendo em vista que não acontece somente com essa pessoa, mas, com uma multidão que se encontra na mesma situação. 


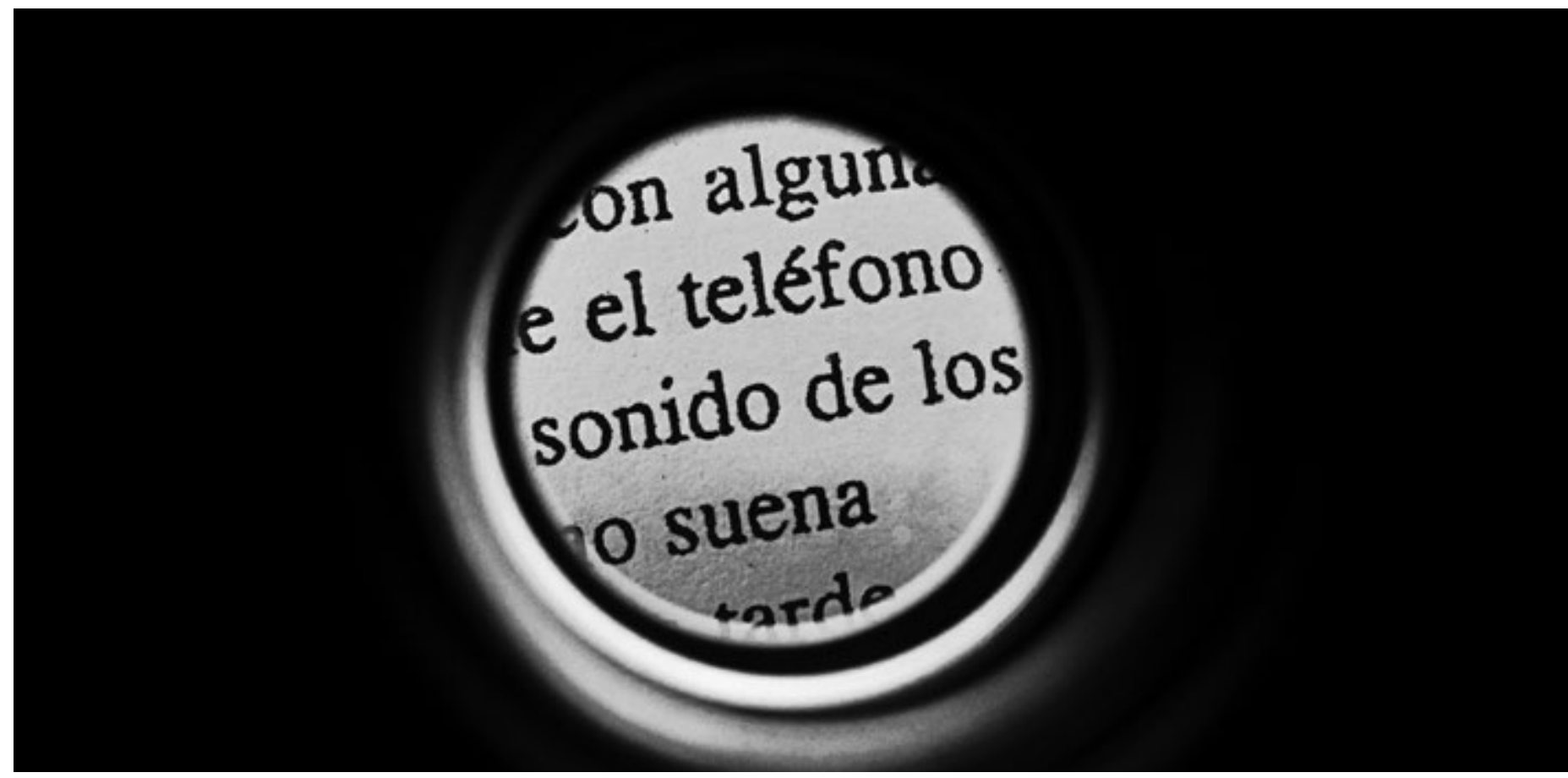

Chamaremos nosso paciente de Senhor A: um homem na época de sua chegada aos serviços com 42 anos de idade (atualmente com 47 anos), que sofrera uma intervenção cirúrgica para a remoção de um tumor na cabeça. O crescimento do tumor afetou o nervo óptico, deixando- o muito fino, causando a perda da visão. Por consequência da retirada do tumor, há quatro anos o Senhor A sofre convulsões, e mesmo com a remoção do mesmo foi submetido a mais quatro cirurgias, com o objetivo de eliminar a água que acumulava no local em que este ficava.

Decorrente dessas intervenções cirúrgicas, o Senhor A quase perdeu totalmente o movimento do braço direito. Atualmente, tem dificuldades para se sentar sozinho, precisando de apoio de outra pessoa para ficar em pé. Na mesma perspectiva, apresenta alterações constantes de humor. Com isso, a própria intervenção psicossocial sofre alterações, uma vez que, ora os efeitos positivos se exacerbam, ora se lentificam e/ou regridem.

Nesta configuração, os atendimentos precisam o tempo todo dialogar com outras atividades e saberes advindo dos atendimentos médicos e de enfermagem. Assim, as buscas de parcerias com outras práticas: sociais, políticas e culturais visam a ressocialização, inclusão do paciente e seus familiares em redes sociais emancipatórias.

Durante os últimos quatro anos de atendimentos tem-se como proposta dar suporte ao Senhor A por ter perdido a visão e incentivá-lo a falar, aumentar sua auto-estima, se expressar e movimentar o seu corpo. Organizamos o trabalho realizado por meio de atendimentos domiciliares que ocorreram duas vezes por semana, complementado por acompanhamento semanal de uma enfermeira da Estratégia Saúde da Família (ESF), fazendo uso de medicamentos anticonvulsivantes, calmantes e remédios para hipertensão.

$\mathrm{O}$ atendimento realizado pela Psicologia tem se instrumentalizado por meio de maior clarificação sobre os significados da cegueira, bem como, do uso de contação de histórias, considerando sempre o contexto sócio-histórico e cultural como pano de fundo político e emancipatório. De modo clarificador, apresentamos considerações sobre a cegueira e as contações de histórias.

\subsection{Deficiência visual: considerações sobre a cegueira} Podemos apresentar a deficiência como um fenômeno construído socialmente, desse modo, no contexto da deficiência visual há diversos conceitos e mitos acerca da mesma. A pessoa cega tem sido ao longo da história, excluída, e podemos evocar algumas concepções populares sobre a cegueira, tais como: a cegueira como punição ou como efeito de poderes sobrenaturais.

De acordo com Franco e Dias (2007) nas sociedades primitivas, acreditavam que as pessoas cegas eram possuídas por espíritos malignos, quando nasciam eram mortos ou abandonados. Durante a Idade Média, a cegueira era vista como castigo ou como um ato de vingança, do mesmo modo que na mitologia grega. Nota- se que por um longo período, as pessoas cegas viveram um processo de desvalorização e de exclusão social. A partir do século XVIII ganham maior visibilidade: primeiro com a criação do Instituto Real dos Jovens Cegos de Paris, que de acordo com Lira e Schlindwein (2008) foi a primeira escola no mundo destinada à educação 


\section{6}

\section{a metodologia de contações de histórias, em interfaces com o acompanhamento terapêutico, pode ser um dispositivo no acompanhamento psicossocial de pessoas comprometidas pela cegueira}

de pessoas cegas, depois em 1829, Louis Braille, aluno desse instituto, inventou o Sistema Braille.

Somente no século XX, especificamente entre a década de 1960 e 1970 , as leis favoreceram o acesso dos cegos à escola regular e ao mercado de trabalho.

No Brasil, segundo Lira e Schlindwein (2008), o atendimento às pessoas com diferenças visuais se iniciou com a fundação do Imperial Instituto de Meninos Cegos, na cidade do Rio de Janeiro, em 1854, pelo Imperador D. Pedro II, que mais tarde recebeu a denominação de Instituto Benjamin Constant.

A visão tida como porta de entrada de informações fundamentais ao ser humano pode implicar em significativas dificuldades na realização de diversas tarefas cotidianas. No contexto fisiológico podemos dividi-las em dois grupos: cegueira e baixa visão - a cegueira pode ser dividida em: congênita ou adquirida. $A$ cegueira congênita advém de condições fisiológicas como a má formação do aparelho ocular. Já a adquirida, provém de traumas oculares, cataratas, ou diabetes. As causas mais comuns são de origem infecciosa: rubéola, toxoplasmose e doenças de causas hereditárias (Manual CBO, 2000).

Essas informações se somam às consequências advindas dos efeitos negativos pós- cirúrgicos vividos por nosso paciente e permite-nos situar a cegueira de Senhor A como adquirida, com isso, detentor de lembranças que nem sempre são tão claras, e que por sua vez lentifica qualquer tentativa de reabilitação. De acordo com Lira e Schlindwein há uma tendência cultural das pessoas videntes considerarem os deficientes visuais como limitados e/ou incapazes. Desta forma:

"Ao se tratar especificamente da educação da pessoa com diferenças visuais, pode-se dizer que a falta de visão é percebida, a priori, como ponto frágil e vulnerável, causando curiosidade, piedade, surpresa e admiração, de forma que a pessoa é vista como dependente, precisando ser guiada, protegida e amparada" (Lira e Schlindwein, 2008:176).

Na proposta de nossas atenções psicossociais, optamos por dar passagens a devires outros, que privilegiam a emergência das estilísticas da existência, ou seja, estilos de viver, voltados para o cuidado de si, orientado por uma ética, estética e política de composição com a vida, que garanta o direito fundamental à singularidade, em oposição a regimes de verdades que se mostram universais. Em consonância com Michel Foucault:

"Deve-se entender com isso uma maneira de viver cujo valor moral não está em sua conformidade a um código de comportamento nem em um trabalho de purificação, mas depende de certas formas, ou melhor, certos princípios formais gerais no uso dos prazeres, nos limites que se observam, na hierarquia que se respeita" (1985:82).

Essas proposições nos permitem mapear processos de subjetivação que não se reduzem a processos de individuação, mas, se ampliam diante das possibilidades de construção de novos sujeitos decorrentes dos processos de subjetivação singulares, que ampliam seus universos de referencias e suas circulações pelo mundo.

\subsection{A arte de narrar e contar histórias}

A arte de contar histórias sempre existiu, desde os primitivos com suas pinturas nas cavernas, na antiguidade entre as tribos, nas quais esses povos contavam histórias para difundirem seus rituais, nos quais contavam seus mitos. Segundo Matos \& Sorcy (2007) o contador de história, já recebeu diversas denominações de acordo com suas culturas e momentos sócio-históricos: rapsodos, griot, bardos.

A partir dessas referências o sujeito que por meio dos contos divulga histórias, sejam elas, reais ou irreais, como as memórias de seus ancestrais, que são contadas de geração em geração, para não serem esquecidas, é aquele que deve se deixar levar pela história. O contador de histórias interage com seus ouvintes, envolve-os não somente pela oralidade, mas pelas expressões corporais, das improvisações e das interações com o público. Essa magia e encanto produzidos pela ação do contar histórias 
estiveram presentes na relação que estabelecemos com o Senhor A. Situamos aqui a arte de contar histórias como dispositivos terapêuticos presentes nos atendimentos e de como proporcionou diversos progressos na reabilitação do Senhor A, vindo ao encontro de como Machado (2004) esclarece que o contar histórias e o trabalho que se possa fazer com elas tem uma função ligada ao papel que o exercício da imaginação e criação desempenha no processo de construção de conhecimento como um todo, pois, o importante não é querer saber qual o efeito que os contos tradicionais exercem sobre o sujeito, ou mesmo "querer produzir tal efeito", mas entender que para cada um a história permite passar pelo reino das possibilidades de resignificar a vida de modo a contribuir com os processos de subjetivação.

\section{Metodologia}

Os atendimentos ocorreram duas vezes por semana com duração de 1 hora cada, sendo os mesmos realizados no domicílio do paciente. Para a realização do atendimento realizamos interfaces entre o acompanhamento terapêutico e contação de história. Para essa atividade escolhemos uma história curta, de modo que tivesse possibilidade de desenvolver diálogos e reflexões, bem como, resgatar histórias pessoais, para que se expressasse e exercitasse a memória, pois, muitas vezes, o paciente não conseguia dizer uma sequência lógica de palavras.

Junto às histórias levamos objetos com base em pesquisas sobre cegueira e com a experiência do próprio atendimento, no qual esses objetos propiciaram melhor entendimento das histórias, exercício de memória e sensibilidade do tato. A proposta da contação de histórias nos insere dentro da metodologia de AT que se caracteriza conforme apontaremos a seguir.

\subsection{Acompanhamento terapêutico}

De acordo com Silva (2005), o acompanhamento terapêutico (AT) emergiu no campo da psiquiatria, em um contexto pós-guerra, no qual ocorreu a criação de hospital de dia; um espaço terapêutico para realizar determinadas atividades, nesse contexto o sujeito tido como louco não precisava ficar na estrutura manicomial, desde que acompanhado por um agente terapêutico. O AT aponta a rua como espaço clínico - espaço de produção de novas subjetividades, possibilitando a prática cartográfica.

Segundo Júnior (2012), no (AT) trata-se de uma modalidade de atendimento psicológico onde o local do trabalho é, justamente, no contexto do paciente; é um modelo de intervenção que ocorre no cotidiano interativo das pessoas. Nesse sentido, fica claro a metodologia do AT como auxiliar político de problematizações psicossociais que leva em consideração o contexto social e cultural, no qual a pessoa está inserida e as negociações políticas possam contribuir com a construção da cidadania em ambientes vulneráveis, clarificando a necessidade de problematizar a clínica de modo ampliado e emancipatório.

\section{Discussão dos resultados}

Finotelli (2012) ressalta a importância da flexibilidade que o terapeuta deve ter para se adequar às demandas do paciente, e desta forma algumas vezes precisávamos nos adaptar com a estrutura oferecida e com as interrupções de parentes. Muitas vezes, ao dialogar com o Senhor $A$, independente se o que contava eram lembranças ou criações, era logo atravessado por alguém que dizia "ele não esta falando nada com nada", colocavam música em volume alto, o que costumava atrapalhar muito os atendimentos. Nessa época, mesmo com muita dificuldade, o Srenhor A andava até a casa de parentes apoiado na esposa, e, quando estava muito fraco era conduzido em uma cadeira de roda.

No início Senhor. A comentava sobre a perda da visão como uma enfermidade, não dizia ser cego e sim "enfermo", dizia ter ficado doente por muito tempo e que não via nada, e por não enxergar nada não tinha vontade de sair muito, apenas recebia visitas e algumas vezes ia para a igreja. Nesta época houve a visita de uma religiosa, que dizia ter tido uma revelação divina de que Deus 


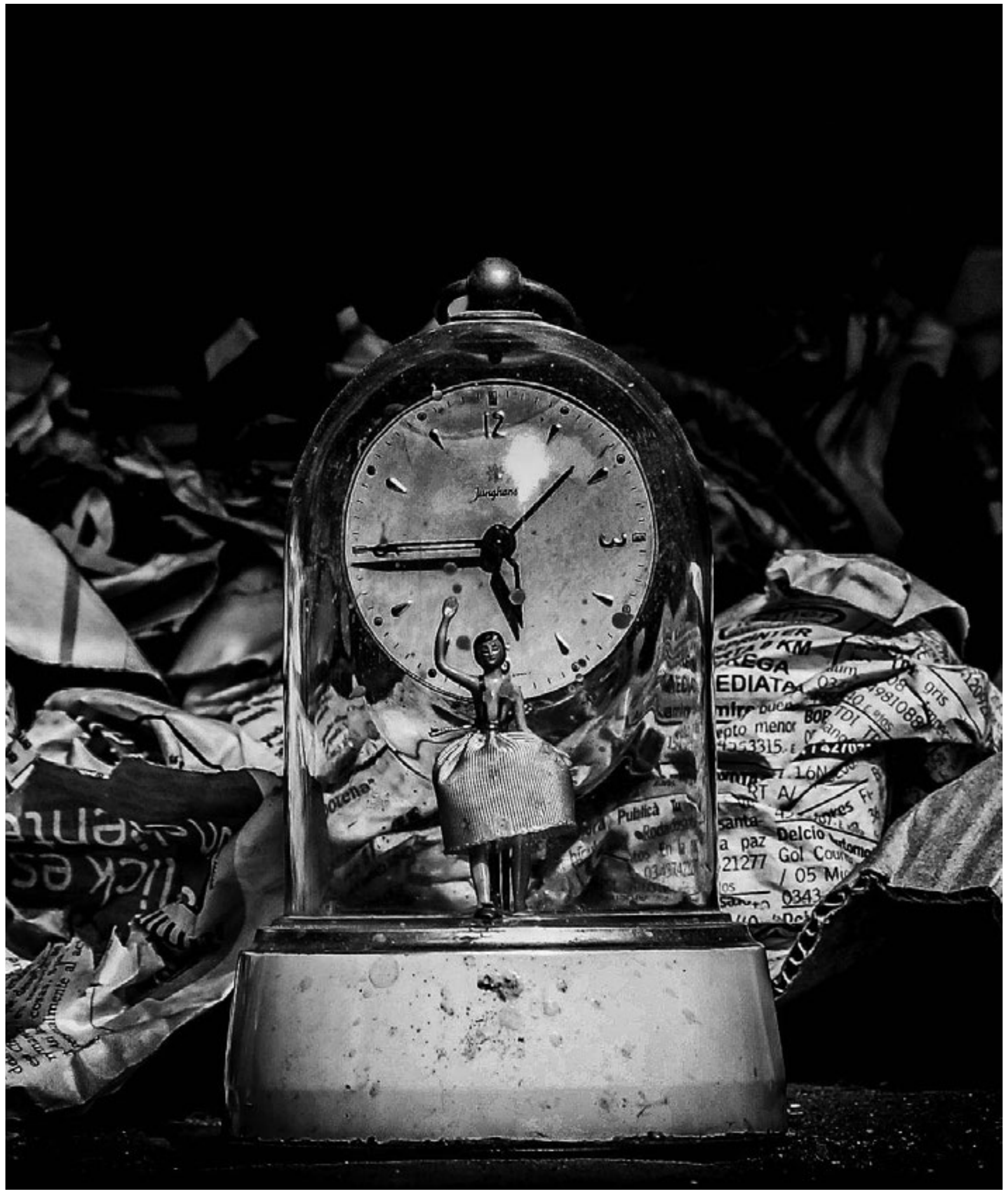


iria operar um milagre e que o mesmo voltaria a enxergar; essa afirmação fez com que o paciente passasse a acreditar no milagre e ficar durante alguns meses a espera deste, que não veio. Ao final do atendimento, não se mostrava revoltado com a perda da visão, falava do "não enxergar", e sobre o desanimo de ir para algum lugar e não poder enxergar. Atualmente, o paciente usa cadeira de rodas para ir à igreja, e não há possibilidade de fazê-lo andar de um cômodo para outro, pois, não consegue ficar muito tempo em pé, tem pouca firmeza nas pernas mesmo se apoiado em alguém. Acreditamos que essa dificuldade decorreu devido às sequências de convulsões que teve durante um mês, ficando internado para tomar medicações que contivesse futuras convulsões. Há uma insegurança no paciente, inclusive, para tentar novos ensaios existenciais possíveis diante da reorganização de uma pessoa com perda da visão. Finotelli (2012) destaca a importância do papel dos outros moradores da casa do acompanhado, a necessidade da medicação de base, a busca de atividades para enriquecer a vida social/funcional e o exercício da autonomia pela compreensão das limitações do paciente. Porém, existem diversas dificuldades para desenvolvermos o exercício da autonomia, muitas vezes, comprometidos pela família, pelo estado físico e efeitos dos medicamentos. A família como principal meio para potencializar o Sr. A em suas atividades, considerando que já houve vezes que ao tentar circular pela casa, os familiares faziamno deitar com a preocupação de que caísse, fato que mudou ao longo dos acompanhamentos.

Apesar da dificuldade de locomoção, a parte física do Sr. A não é de todo comprometida, trabalhamos por um tempo a questão que o próprio paciente trouxe, de não se alimentar sozinho devido ao comprometimento do braço direito, da cegueira, e por isso, a família acostumou alimentá-lo. Ou seja, há um comprometimento da própria família em se inserir no itinerário terapêutico proposto. O Sr. A, por mais que tenha comprometimentos físicos, tais como, paralisação do braço direito, da visão e mesmo a questão da memória prejudicada não teria necessidade de ficar o dia inteiro deitado, pois, consegue atualmente com alguma dificuldade sentar sozinho, realizar alguns movimentos como beber água, tatear objetos e nomeá-los, embora, as atividades básicas como banho, utilização do banheiro e higiene pessoal ainda precisam da ajuda da esposa. Orientamos que mesmo a alimentação que era realizada no quarto, poderia ser feita em outro espaço, como forma de incentivá-lo a ampliar sua circulação pela casa. Essas percepções nos levaram a pontuar, que não se tratava de um sujeito doente, mas, poderia ampliar sua "visão" particular como outro sujeito, que precisa resignificar seus conceitos, valores sobre si e os outros. Tratava-se de políticas relacionais que solicitavam negociações para a emergência de novas estilísticas de existência. Em conjunção com os procedimentos psicossociais somamos o uso de medicação tais como: anticonvulsivantes, calmantes e remédios para hipertensão. Nossas observações indicavam que o uso de calmantes parecia "colaborar" para que ele ficasse deitado tanto tempo, o remédio era tomado de 12 em 12 horas, e causava sonolência, havia indícios e relatos que às vezes tomava um a mais, de que assim ele ficava menos agitado, caracterizando uma demanda da família em tê-lo controlado.

A família aparentemente tinha uma dinâmica pouco ativa, os filhos e a filha estudavam e a esposa trabalhava fora de casa, portanto, havia um tempo que o Sr. A ficava sozinho, mas recebia "vigilância" do parente que morava na casa da frente do domicílio; isso por sua vez, lentificava os resultados de nosso trabalho; isso contribuía para nos sentirmos angustiados e ansiosos por não vê- lo mais autônomo e independente.

Dialogamos com a família a fim de repensar atividades que podiam ser feitas para estimular o Sr. A, que eles pudessem colaborar juntamente com o atendimento e promoção de ressocialização do mesmo, abrindo espaço para que a própria família pudesse colocar suas queixas e questionamentos acerca da situação na qual o encontravam, após, os atendimentos, o que por sua vez significaria que a família também entraria em análise.

Notamos que as conversas com a família sobre o que tínhamos realizado nos atendimentos aos poucos foram causando pequenos efeitos na dinâmica familiar em relação ao paciente. Os incentivos por parte de familiares para o Sr. A poder sentar, comer sozinho, e conversar durante o atendimento de forma a colaborar com os diálogos passaram a ser frequentes.

Esse trabalho tinha pouca base teórica e muita experimentação, era bem lento, precisávamos notar com maior sensibilidade o que era pertinente trabalhar com o Sr. A como e de que forma era positivo ou não determinadas atividades, o que implicava avaliações permanentes para a tomada de decisão dos procedimentos seguintes. Ressaltamos que até o momento o melhor dispositivo tinha sido as histórias contadas e problematizadas com o Sr. A, pois, a partir delas conseguimos fazer diversos ganchos, desde que, os contos vinham sempre carregados de significados e afetos que podiam remeter às histórias pessoais do paciente e suas possíveis reconexões.

Durante as contações de histórias percebíamos que as mesmas proporcionavam alguns progressos na fala e na memória, devido a perguntas "gostou do conto? o que o conto remeteu?, quais personagens podiam ser lembrados?". Toda essa progressão se seguia por semanas, e quanto mais dinâmica fosse à história, notávamos maior interesse por parte do Sr. A, ficando mais animado, conversando mais, com sequência lógica de pensamento, expressava melhor sua afetividade e com as interações com objetos melhorava sua coordenação psicomotora, mas as convulsões ocorriam com frequência intermitente, visto que tudo que o Sr. A progredia podia regredir caso tivesse as convulsões novamente. Porém, mesmo afetado pelas convulsões, podia 


\section{o acompanhamento terapêutico \\ emergiu no campo da psiquiatria, em um contexto pós-guerra, no qual ocorreu a criação de hospital de dia}

na mesma semana progredir, rapidamente, e resignificar suas posições diante da vida.

Havia outro fator de interferência na continuidade do trabalho as férias das estagiárias - uma vez que, ao retomar o trabalho percebíamos que havia tido regressão, pois as atividades deixavam de ser continuas, e, atentando a esse fator, foram dadas dicas de atividades para que a família continuasse estimulando o Sr. A durante as férias: que as histórias fossem contadas pelo menos duas ou três vezes por semana, que o fizessem sentar e realizasse pequenas caminhadas, que conversassem com ele sobre o cotidiano da família, informasse se mudou algum objeto ou móvel de lugar, enfim, que positivasse a situação para além da ideia de doença e considerassem a cegueira como uma estilística de viver. Para Finotelli (2012) o papel do AT é um recurso, no qual acompanhantes e acompanhados reinventam modos de se relacionar e estar no mundo. No caso do Sr. A, com o tempo ele passou a não falar mais da sua condição como enfermidade, mas, da cegueira ampliada que permitia resignificar seu lugar no mundo e que existem outras formas de enxergar, passou a opinar sobre o que gosta e não gosta mais assertivamente.

\section{Considerações finais}

O AT promoveu buscas e realizações de atividades para o acompanhado e com isso incentivamos o Senhor A se movimentar usando de outros artifícios terapêuticos, tais como: instrumentos musicais artesanais, os livros das contações de histórias, ou até mesmo convencer que sentar faz bem para o corpo e para a mente. Além da importância de movimentar-se, como modo de enfrentar a emergência de escaras produzidas pelo excesso da paralisação do corpo sobre a cama.

Os atendimentos possibilitaram a reabilitação e possibilidades de transformação nos modos de suas vivências, a fim de proporcionar independência e autonomia de seus quereres e fazeres. Por mais que existam oscilações entre progredir e regredir, foi possível notar com base no que foi trabalhado nesses anos que o Sr. A "evolui cada vez mais", mesmo com lentidão, na qual as progressões são percebidas sutilmente.

Mello (2010) em uma discussão sobre $A$ construção da Pessoa na Experiência da Deficiência problematiza qual seria o limite entre ser uma pessoa e ter uma deficiência, ou como as pessoas com deficiência se colocam no mundo? Essas questões vão ao encontro do nosso atendimento, já que o Sr. A ficou deficiente e o processo para reconhecer a perda da visão foi demorado. Primeiro, devido à própria perda da visão, seguido do anúncio da salvação pela religião. Segundo, pela memória confusa que tomou a falta de visão como uma doença que a qualquer momento poderia ser curada. Seria importante ressaltar que o fato de perder a visão e ter dificuldades para locomoção acarretou a transformação de um corpo doente, que fica deitado o tempo todo na cama, sendo corroborado por essa mesma crença entre seus familiares.

Os atendimentos proporcionaram a percepção do novo corpo e quais eram as novas possibilidades e relações que poderiam ser resignificadas. $\mathrm{O}$ que antes era dito como enfermidade; passa a ser dito com o tempo cada vez mais resignificado, já que enxergar, não é só com os olhos, mas, com o tato, os sons, os cheiros e sabores. Segundo Mello (2010) a pessoa com deficiência precisa estar inserida em um ambiente propício à promoção de sua auto-estima, autoconfiança e desejo de mudança, adquirindo a habilidade necessária para enfrentar de forma aberta e construtiva seus conflitos existenciais. Podemos a partir dessa constatação, problematizar outras formas que esse corpo possa se localizar, como uma pessoa além de ter dificuldades de locomoção, memória e ser usuário de medicamentos anticonvulsivos, não se restringe a isso. Isso solicita ainda problematização sobre aquilo que Michel Foucault denominou de "cuidado de si", ao clarificar que:

"é preciso entender que o princípio do cuidado de si adquiriu um alcance bastante geral: o preceito segundo o qual convém ocuparse consigo mesmo é em todo caso um imperativo que circula entre numerosas doutrinas diferentes; ele também tomou a forma de uma atitude, de uma maneira de se comportar, impregnou formas de viver; desenvolveu-se em procedimentos, em práticas e em receitas que eram refletidas, desenvolvidas, aperfeiçoadas e ensinadas; ele constitui assim uma prática social, dando lugar a relações interindividuais, a trocas e comunicações e até mesmo a instituições; ele proporcionou, enfim, um certo modo de conhecimento e a elaboração de um saber" (Foucault, 1985:50).

Portanto, o cuidado de si construído pelos modos de subjetivação normatizadores, aquele que impõe modelos de corpos saudáveis 
e perfeitos, quando problematizados em referência aos corpos dissidentes, como é o caso do Sr. A, solicita a construção de novas conceituações a respeito de cuidado de si, pois não se trata de reducionismos limitados a crença de um corpo único de referência, mas de miríades de corporalidades possíveis que se inscrevem no mundo como diferenças.

Essa nova possibilidade de cuidar de si solicita uma revisão e ampliação conceitual que favorece a emergência de uma estilística de viver, e, dentro de nossos procedimentos buscamos resgatar potencias até então adormecidas que possam fazer do Sr. A, buscar invenção de novas formas de relação consigo mesmo, com esse novo corpo, com outras possibilidades de conexão com a vida que não se restrinja ao modelo normativo dado anteriormente, mas que invente outras sensações e crenças de outro corpo que possa viver, amar e se relacionar com outra configuração que permita se reconhecer como sujeito positivado do desejo.

Construímos a partir desse AT e as Contações de Histórias, tentativas de colocar novas questões quanto às práticas da Psicologia em seus atendimentos. A utilização do contar histórias permitiu o resgate das histórias pessoais do Sr. A e possibilitou novas formas de "enxergar o mundo", bem como, elevar sua autoestima pela potencialidade para poder sentir, pensar, levantar, andar, enfim, desejar outros possíveis. Recebia visitas de amigos, enfermeiras, estagiários de psicologia e conversa com a família, entretanto, não tem lazer - pouco passeia, uma vez que, depende de outras pessoas, além do comprometimento econômico que limita o acesso a bens e serviços de qualidade. Ressaltamos ainda, os adultos em sua maioria quando perdem a visão se "rotulam ou são rotulados" como incapazes, ou inativos - como perdessem a "vida ativa" não sendo capaz de reestruturar o novo modo de se "inserir" no mundo. Sr. A tem possibilidades de realizar diversas atividades, busca-se "transformar", resignificar esse corpo não ocupando mais o lugar de doente, mas, um corpo que tem potência.

\section{Referências}

Finotelli J.I. (mai/jun de 2012). "Teorias e práticas no campo do acompanhamento terapêutico". Psico- USF, Vol. 17, № 2.

Foucault, M. (1985). História da sexualidade: o uso dos prazeres. Vol. 03. Rio de Janeiro, Editora Graal.

Franco, J.R.; Dias, T.R.S. (2007). A educação de pessoas cegas no Brasil. Avesso do Avesso Araçatuba, v. 5, p. 74-81.

Machado, R. (2004). Acordais: fundamentos teóricos- poéticos da arte de contar histórias. São Paulo, DCL.

Matos, G \& Sorsy, I. (2007). O Oficio do contador de histórias. São Paulo: Martins Fontes.

Mello, A.G. (2010). "A construção da pessoa na experiencia da deficiência: corpo, gênero, sexualidade, subjetividade e saúde mental". In: Maluf, S. W.; Tornquist, C.

S. (org.). Gênero, saúde e aflição: abordagens antropológicas. Florianópolis, Letras Contemporâneas, 2010. p. 133-191.

Tornquist, C.S. (orgs) (2010). Gênero, Saúde e Aflição: abordagens antropológicas Florianópolis: Letras Contemporâneas.

Silva, A.S.T. (2005). A emergência do acompanhamento terapêutico: O processo de constituição de uma clínica. Dissertação de Mestrado em Psicologia Social e Institucional. 